\title{
Is aneurysm surgery too exciting for our own good?
}

\author{
Ole Solheim $^{1,2}$
}

Received: 8 December 2015 / Accepted: 14 December 2015 / Published online: 28 December 2015

(C) Springer-Verlag Wien 2015

Bunevicius and colleagues present an observational study on hemodynamic changes recorded from four experienced vascular neurosurgeons during 42 aneurysm clippings (ref). With this rather novel approach studying surgeons instead of patients, they found that heart rates and blood pressures rose during surgery and peaked after aneurysm neck dissection and clipping relative to at rest. They also observed that clipping un-ruptured aneurysms was associated with greater hemodynamic responses than clipping ruptured aneurysms. Although they are to be congratulated for conducting an interesting and different study, it may hardly come as a surprise to the reader that aneurysm surgery can be more stressful than resting in a chair. It also seems reasonable that un-ruptured aneurysms trigger greater hemodynamic responses since only perfect results are acceptable when patients undergo prophylactic neurovascular surgery, while treatment results in patients with subarachnoid hemorrhage are not entirely up to the surgeon. Although too much stress may increase tremor, impair judgment and therefore be undesirable for our patients during complex microneurosurgical procedures, the authors also speculate that aneurysm surgery may pose an occupational threat to our own health.

Despite stressful surgeries, the mortality rates of surgeons luckily do not appear to be higher than in other medical specialties, and there is no excess of ischemic heart disease [1, 17]. In Norway, the life expectancy of male doctors is among

Ole Solheim

ole.solheim@ntnu.no

1 Department of Neurosurgery, St. Olavs University Hospital, Trondheim, Norway

2 Department of Neuroscience, Norwegian University of Science and Technology, Trondheim, Norway the highest of all professions; only priests, college/university teachers and architects beat us by a few months (www.ssb.no). US data also confirm that the life expectancy is higher for physicians than for example lawyers and other examined professionals [3]. But are neurovascular surgeons perhaps special?

Although neurovascular surgery is both technically and mentally demanding, dealing with as well as controlling stress is part of the drill. Many neurovascular surgeons thrive on stress and may therefore represent a selection of individuals who are more comfortable with stressful situations. With human responses there is often a response shift with repeated exposures over time. With experience many neurovascular surgeons may therefore become more resistant to the adverse reactions from stress, as also suggested in the current study. This is presumably good for our patients. Among the four experienced neurovascular surgeons included in the present study, recorded hemodynamic responses were quite modest with observed heart rates $<100$ per minute and systolic blood pressures less than $140 \mathrm{mmHg}$ during all phases of surgery. Although there was no continuous recording of heart rates or blood pressures, another small study that recorded data every 10 min observing five neurosurgeons clipping ten aneurysms and removing one vestibular schwannoma observed more severe increases (systolic/diastolic blood pressure $>180$ / $110 \mathrm{mmHg}$ ) $28 \%$ of the time during observation. Also, abnormal blood pressure was more common during surgery than during vigorous physical exercise [14]. Even so, based on what we know from these two studies, aneurysm surgery does not seem to trigger extreme hemodynamic responses compared to other procedures or life situations. Similar hemodynamic responses have for example been seen during hallux valgus surgery, but with larger responses in trainees than in trainers [5]. Also in healthy men watching (Scottish!) football hemodynamic responses similar to performing aneurysm 
surgery were seen, even though most rated the matches as relatively unexciting [2]. For comparison, hemodynamic responses to sexual activity can be far greater than both watching unexciting football matches and clipping intracranial aneurysms [15]. Is it still possible that the strain from years of arousals during neurovascular surgeries can take its toll?

Despite decades of research, stress is still not accepted as an independent risk factor for cardiovascular disease. Although, epidemiological studies report an association between job strain and stroke [7] , coronary heart disease [8], diabetes [11], and depression [10], these associations are not necessarily causal, since stress is associated with a number of unhealthy lifestyle factors $[4,6,12]$ such as physical inactivity, unhealthy diets, smoking, and excessive alcohol consumption. Also, relations among stress, angina, and hospital admissions in observational studies may be affected by the fact that participants reporting higher stress levels also report more symptoms and may have increased detection rates [9]. It is therefore still not clear whether elevation of the heart rate or blood pressure due to stress is harmful per se.

Even so, in persons with atherosclerosis or established vascular disease, stress with hemodynamic responses may trigger plaque rupture, thrombotic vessel occlusion, and cardiovascular events. During the 2006 Fédération Internationale de Football Association (FIFA) World Cup in Germany, it was observed that the incidence of cardiac emergencies was much higher on days when the German team played than in the control periods. However, the proportion of patients with known coronary heart disease was also much higher among admitted patients on days when the German team played [16]. Thus, just like sexual intercourse may trigger rupture of intracranial aneurysms [13], watching football may trigger cardiovascular events in patients with established coronary disease. Luckily, there is still no evidence that involvement in sexual activity or football watching is causing intracranial aneurysms or coronary heart disease, and for now we should worry more about our patients' health than our own when clipping aneurysms.

\section{References}

1. Carpenter LM, Swerdlow AJ, Fear NT (1997) Mortality of doctors in different specialties: findings from a cohort of 20000 NHS hospital consultants. Occup Environ Med 54:388-395

2. Elder AT, Jyothinagaram SG, Padfield PL, Shaw TR (1991) Haemodynamic response in soccer spectators: is Scottish football exciting? BMJ (Clin Res Ed) 303:1609-1610

3. Frank E, Biola H, Burnett CA (2000) Mortality rates and causes among US physicians. Am J Prev Med 19:155-159

4. Fransson EI, Heikkila K, Nyberg ST, Zins M, Westerlund H, Westerholm P, Vaananen A, Virtanen M, Vahtera J, Theorell T, Suominen S, Singh-Manoux A, Siegrist J, Sabia S, Rugulies R, Pentti J, Oksanen T, Nordin M, Nielsen ML, Marmot MG, Magnusson Hanson LL, Madsen IE, Lunau T, Leineweber C,
Kumari M, Kouvonen A, Koskinen A, Koskenvuo M, Knutsson A, Kittel F, Jockel KH, Joensuu M, Houtman IL, Hooftman WE, Goldberg M, Geuskens GA, Ferrie JE, Erbel R, Dragano N, De Bacquer D, Clays E, Casini A, Burr H, Borritz M, Bonenfant S, Bjorner JB, Alfredsson L, Hamer M, Batty GD, Kivimaki M (2012) Job strain as a risk factor for leisure-time physical inactivity: an individual-participant meta-analysis of up to 170,000 men and women: the IPD-Work Consortium. Am J Epidemiol 176:10781089

5. Gupta HO, Gupta S, Carter RL, Mohammed A, Meek RM (2012) Does orthopaedic surgical training induce hypertension? A pilot study. Clin Orthop Relat Res 470:3253-3260

6. Heikkila K, Fransson EI, Nyberg ST, Zins M, Westerlund H, Westerholm P, Virtanen M, Vahtera J, Suominen S, Steptoe A, Salo P, Pentti J, Oksanen T, Nordin M, Marmot MG, Lunau T, Ladwig KH, Koskenvuo M, Knutsson A, Kittel F, Jockel KH, Goldberg M, Erbel R, Dragano N, DeBacquer D, Clays E, Casini A, Alfredsson L, Ferrie JE, Singh-Manoux A, Batty GD, Kivimaki M (2013) Job strain and health-related lifestyle: findings from an individual-participant meta-analysis of 118,000 working adults. Am J Public Health 103:2090-2097

7. Huang Y, Xu S, Hua J, Zhu D, Liu C, Hu Y, Liu T, Xu D (2015) Association between job strain and risk of incident stroke: a metaanalysis. Neurology 85:1648-1654

8. Kivimaki M, Nyberg ST, Fransson EI, Heikkila K, Alfredsson L, Casini A, Clays E, De Bacquer D, Dragano N, Ferrie JE, Goldberg M, Hamer M, Jokela M, Karasek R, Kittel F, Knutsson A, Koskenvuo M, Nordin M, Oksanen T, Pentti J, Rugulies R, Salo P, Siegrist J, Suominen SB, Theorell T, Vahtera J, Virtanen M, Westerholm PJ, Westerlund H, Zins M, Steptoe A, Singh-Manoux A, Batty GD (2013) Associations of job strain and lifestyle risk factors with risk of coronary artery disease: a meta-analysis of individual participant data. CMAJ: Can Med Assoc J = J de l'Assoc Med Can 185:763-769

9. Macleod J, Davey Smith G, Heslop P, Metcalfe C, Carroll D, Hart C (2002) Psychological stress and cardiovascular disease: empirical demonstration of bias in a prospective observational study of Scottish men. BMJ (Clin Res Ed) 324:1247-1251

10. Global SPI (2013) Study protocol for examining job strain as a risk factor for severe unipolar depression in an individual participant meta-analysis of 14 European cohorts. F1000 Res 2:233

11. Nyberg ST, Fransson EI, Heikkila K, Ahola K, Alfredsson L, Bjorner JB, Borritz M, Burr H, Dragano N, Goldberg M, Hamer M, Jokela M, Knutsson A, Koskenvuo M, Koskinen A, Kouvonen A, Leineweber C, Madsen IE, Magnusson Hanson LL, Marmot MG, Nielsen ML, Nordin M, Oksanen T, Pejtersen JH, Pentti J, Rugulies R, Salo P, Siegrist J, Steptoe A, Suominen S, Theorell T, Vaananen A, Vahtera J, Virtanen M, Westerholm PJ, Westerlund H, Zins M, Batty GD, Brunner EJ, Ferrie JE, Singh-Manoux A, Kivimaki M (2014) Job strain as a risk factor for type 2 diabetes: a pooled analysis of 124,808 men and women. Diabetes Care 37: 2268-2275

12. Nyberg ST, Fransson EI, Heikkila K, Alfredsson L, Casini A, Clays E, De Bacquer D, Dragano N, Erbel R, Ferrie JE, Hamer M, Jockel KH, Kittel F, Knutsson A, Ladwig KH, Lunau T, Marmot MG, Nordin M, Rugulies R, Siegrist J, Steptoe A, Westerholm PJ, Westerlund H, Theorell T, Brunner EJ, Singh-Manoux A, Batty GD, Kivimaki M (2013) Job strain and cardiovascular disease risk factors: meta-analysis of individual-participant data from 47,000 men and women. PLoS One 8, e67323

13. Reynolds MR, Willie JT, Zipfel GJ, Dacey RG (2011) Sexual intercourse and cerebral aneurysmal rupture: potential mechanisms and precipitants. J Neurosurg 114:969-977

14. Sharma MS, Thapa A, Chandra SP, Suri A, Singh M, Bahl VK, Sharma BS (2010) Intraoperative pulse and blood pressure 
recordings of neurosurgeons: a pilot study of cardiovascular performance. Neurosurgery 66:893-899, discussion 899

15. Stein RA (2000) Cardiovascular response to sexual activity. Am J Cardiol 86:27F-29F

16. Wilbert-Lampen U, Leistner D, Greven S, Pohl T, Sper S, Volker C, Guthlin D, Plasse A, Knez A, Kuchenhoff H, Steinbeck G (2008)
Cardiovascular events during World Cup soccer. N Engl J Med 358: 475-483

17. Wright DJ, Roberts AP (1996) Which doctors die first? Analysis of BMJ obituary columns. BMJ (Clin Res Ed) 313:1581-1582 